\title{
I'm Like You and You're Like Me: Social Projection and Self-Stereotyping Both Help Explain Self-Other Correspondence
}

\author{
Jeff C. Cho and Eric D. Knowles \\ University of California, Irvine
}

\begin{abstract}
Social projection and self-stereotyping are rival explanations for self-other correspondence, in which people tend to perceive a high degree of similarity between themselves and others. The present research shows that both accounts are correct-that is, that knowledge of the self and knowledge of others are mutually constraining. In Study 1, participants whose self-views were experimentally manipulated revised their judgments of an immediate ingroup. In Study 2, an analogous manipulation of ingroup traits altered participants' self-views. In Study 3, participants who were ascribed a trait readily projected to and stereotyped from their relevant ingroup, but not to or from an outgroup. Finally, Study 4 provides reaction-latency evidence for social projection and self-stereotyping as judgmental processes leading to self-other correspondence. In this task, participants referenced self-knowledge when reaching ingroup-descriptiveness judgments (evidence for social projection) and ingroup knowledge when judging the self (evidence for self-stereotyping). Implications for the debate between protocentric and egocentric accounts of person perception are discussed.
\end{abstract}

Keywords: social projection, self-stereotyping, social identity, social judgment

You and I are alike in many ways... I'm like you and you're like me._Cindy Gainer, I'm Like You, You're Like Me

We tend to overestimate the degree of similarity between others and ourselves. In their classic demonstration of the false-consensus effect, Ross, Greene, and House (1977) provided one of the best-known examples of "self-other correspondence." In this study, college students who complied with an experimenter's request to wear a sandwich board advertisement expected a majority of their fellow students to behave in kind, whereas participants who refused the request expected their peers to prove similarly uncooperative. Since this touchstone experiment, many studies have documented individuals' tendency to overestimate the match between their own and others' personal qualities, including beliefs and attitudes (for a review, see Marks \& Miller, 1987), bodily states such as hunger and thirst (Van Boven \& Loewenstein, 2003), and behavioral tendencies such as showering (Monin \& Norton, 2003) and cheating on tests (Katz \& Allport, 1931).

Many theorists attribute self-other correspondence to social projection: We expect that "other people are like me" and project onto them what we know about ourselves. As Clement and Krueger (2000) note, however, most patterns of perceived

This article was published Online First December 31, 2012.

Jeff C. Cho and Eric D. Knowles, Department of Psychology and Social Behavior, University of California, Irvine.

Eric D. Knowles is now at the Department of Psychology, New York University.

Correspondence concerning this article should be addressed to Jeff C. Cho, Department of Psychology and Social Behavior, University of California, Irvine, CA 92697-7085. E-mail: jccho@uci.edu self-other similarity are subject to an alternative interpretation. In the case of the sandwich board study, students may have agreed to wear the advertisement because they expected other students to show such willingness, whereas those who declined may have regarded noncompliance as their peers' typical response. This process, commonly termed self-stereotyping, suggests that self-ingroup correspondence emerges when we assume that "I am like others" and introject our assumptions about the ingroup.

Which account is correct? The literature's many demonstrations of self-other correspondence are broadly consistent with either social projection or self-stereotyping, and few experiments effectively adjudicate between these explanations. In the present research, we propose that both camps are correct-that the selfconcept and social knowledge are mutually constraining. Consistent with mutual constraint, we show that the causal link between self and ingroup is bidirectional: Experimentally induced changes in the self-concept are projected to a salient ingroup (Study 1), and manipulated changes in an ingroup stereotype are introjected to the self (Study 2). Furthermore, we show that group membership moderates projection and self-stereotyping, such that neither process occurs when the target or source of judgment is an outgroup (Study 3). Finally, we examine whether social projection and self-stereotyping are equally robust causes of self-other correspondence. In a reaction time paradigm, we show that social projection and self-stereotyping both serve as judgmental strategies that "fill in the gaps" when knowledge of the ingroup or self is uncertain or absent (Study 4). The picture that emerges is one in which projection and self-stereotyping processes-rather than being mutually exclusive theoretical options - represent equally important sources of knowledge (for a similar view, see Ames, 2004a, 2004b) 


\section{Social Projection}

Variously referred to as social projection (Krueger, 2007), selfanchoring (Cadinu \& Rothbart, 1996), or self-as-informational base (Gramzow, Gaertner, \& Sedikides, 2001), egocentric explanations of self-other correspondence portray the self as the starting point for social judgment. On this view, judgments about the group are made via an inductive process of self-to-other inference. Some theorists trace egocentric social perception to self-protective or self-enhancing motivations (Pyszczynski, Greenberg, Solomon, Arndt, \& Schimel, 2004), whereas others emphasize selective attention and biased processing of self-related information (Greenwald, 1980; Markus, 1977). More recently, projection has been characterized as an automatic process occurring mainly outside of consciousness and intentional control. This account meshes well with egocentric models of theory of mind (Birch \& Bloom, 2007; Gordon, 1986), according to which judgments of other minds are spontaneously anchored on the self and only then effortfully (and inadequately) adjusted in light of target-relevant information (Epley, Keysar, Van Boven, \& Gilovich, 2004). The egocentric view also gains support from neuroimaging investigations of "mirror circuits." In an illustrative study, Mitchell, Banaji, and Macrae (2005) observed increased activity in the ventral medial prefrontal cortex, an indicator of self-referencing, when individuals inferred the mental states of similar others. In sum, the social projection approach contends that we cannot help but project ourselves onto others-and, accordingly, that self-other correspondence is the direct result of social projection.

A great deal of indirect evidence favors the social projection account. Self-judgments are faster and more easily made than group judgments (Clement \& Krueger, 2000), attesting to the fact that people have privileged access to self-knowledge. The selfconcept is so stable a structure that Greenwald (1980) likened it to a totalitarian regime, suggesting that self-judgments provide a strong foundation on which to build knowledge of others (Krueger \& Stanke, 2001). The self is also highly relevant to individuals: Meta-analytic evidence suggests that one's personal identity is more reactive to threats and affirmations than one's social identity (Gaertner, Sedikides, Vevea, \& Iuzzini, 2002). To the extent that self-knowledge is more salient, stable, and motivationally primary, the social projection account of self-other correspondence appears eminently well-founded.

Despite indirect evidence for the primacy of the self in social judgment, few experimental studies have directly tested the social projection account, and those experiments that have been conducted present a mixed picture. Cadinu and Rothbart (1996) examined social projection in the context of the minimal group paradigm. After being assigned to ingroups, participants received feedback about themselves on unfamiliar traits. Participants readily generalized new self-traits to the ingroup, providing direct evidence that self-knowledge exerts a causal influence on social perceptions. However, Critcher and Dunning (2009), using a bogus personality test to manipulate individuals' self-perceived standing on novel traits, failed to uncover clear evidence for the projection of those traits onto peers (although they did find evidence for projected patterns of association between multiple traits).

\section{Self-Stereotyping}

Social projection is a theoretically sufficient, but not necessary, explanation for self-other correspondence; self-stereotyping, too, may lead us to overestimate how similar we are to others. Selfstereotyping is implied by social identity theory (Tajfel \& Turner, 1986) and explicitly posited by self-categorization theory (Turner, Hogg, Oakes, Reicher, \& Wetherell, 1987), according to which individuals define themselves in terms of the group and its prototypical attributes. Self-categorization theory characterizes selfstereotyping as a dynamic process whereby the self can be rapidly reconstrued at the personal or group level. As such, selfstereotyping increases when the intergroup context is highly salient and relevant, and when ingroup identification is strong (Haslam, Oakes, Reynolds, \& Turner, 1999).

Karniol (2003) proposed that self-stereotyping-in the sense of self-perceptions being grounded in social knowledge-can happen outside the intergroup context. According to Karniol's "self-asdistinct" model, social perception begins with assumptions about what the typical person is like. Our generic representation of the prototypical other (the "protocenter") then serves as a template for understanding both specific others and the self. This account posits that we define ourselves in terms of differentiation from the protocenter, "tagging" attributes that set us apart from it. Accordingly, self-other correspondence occurs to the extent that attributes have not (yet) been tagged as differentiating the self from the protocenter. Contrary to egocentric models of person perception (Krueger, 2003; Mussweiler, 2003; Sedikides, 2003), which posit a self-to-ingroup process of projection, the self-as-distinct model portrays self-judgments as the result of other-to-self introjection.

Consistent with the self-stereotyping hypothesis, research on social influence reveals just how readily people assimilate others' beliefs and attributes as their own. As people conform, comply, or are otherwise influenced by perceived social norms (Cialdini \& Trost, 1998), perceptions of self-other similarity are the natural result of comparison processes (Festinger, 1954). Recent findings suggest that self-stereotyping can take place via even subtler forms of social referencing. Research on "social tuning" suggests that the desire to affiliate is sufficient to make us conform our implicit attitudes to others' (Lowery, Hardin, \& Sinclair, 2001). Similar findings suggest that one can "catch" attitudes, perceived traits, or behaviors merely by priming (Bargh, Chen, \& Burrows, 1996) or thinking about another person (Galinsky, Wang, \& Ku, 2008). In a clever reversal of Katz and Allport's (1931) classic study of cheaters, Gino, Ayal, and Ariely (2009) demonstrated that observing another cheat increases one's own dishonest behaviors. This and other demonstrations of attitude contagion are consistent with the self-stereotyping approach.

Few experiments have directly tested the causal impact of ingroup impressions on self-knowledge. The study by Cadinu and Rothbart (1996) is an exception. In the authors' final experiment, a subset of participants was told that their (minimal) ingroup possessed certain unfamiliar traits. In contrast to their penchant for social projection, participants showed little tendency to generalize novel ingroup traits to the self. Although the authors regard this finding as disfavoring self-stereotyping, it may be that the minimal group paradigm stacks the deck against this process. Not only did participants lack a definite group representation from which to self-stereotype, they may also have lacked sufficient ingroup iden- 
tification to instigate self-stereotyping in the first place (Haslam et al., 1999). We believe that a better experimental test of selfstereotyping would manipulate individuals' perceptions of a salient and meaningful ingroup and examine subsequent changes in self-perceived traits (for a similar view, see Otten, 2004; for a contrary view, see Robbins \& Krueger, 2005).

\section{Social Projection and Self-Stereotyping as Causes of Self-Other Correspondence}

Social projection and self-stereotyping each have clear merits as explanations for self-other correspondence; however, neither explanation accounts for the totality of relevant evidence. We therefore propose that social projection and self-stereotyping both constitute important sources of perceived self-other similarity. Connectionist and parallel constraint-satisfaction models of the self-concept and social knowledge provide clear theoretical grounding for this claim (e.g., Dunning, 2003; Read, Vanman, \& Miller, 1997; Smith, 1996). Whereas traditional models of social cognition suggest that self-concepts and social knowledge are linked by processes that are serial (e.g., egocentric anchor-andadjustment; Epley et al., 2004) and unidirectional (e.g., self-asdistinct model; Karniol, 2003) in nature, connectionist and constraint-satisfaction models postulate that cognitive representations of self and others are processed and altered in parallel. An important feature of such models is mutual constraint, according to which self-knowledge inevitably influences impressions of one's ingroup and representations of ingroups constrain beliefs about the self (Balcetis \& Dunning, 2005).

Social-cognitive research based in a connectionist approach to mental representation (Smith, Coats, \& Walling, 1999; Smith \& Henry, 1996) provides good reason to believe that concepts of self and group are, in fact, mutually constraining. Smith and Henry (1996) found that, when making timed self-descriptiveness judgments, individuals responded more slowly to traits seen to distinguish the self from ingroup (self-ingroup "mismatch" traits) than those seen as common to the self and ingroup (self-ingroup "match" traits). This pattern suggests that participants reflexively consulted social knowledge when making judgments about the self. Subsequent studies revealed a symmetrical pattern in which perceived self-ingroup similarly facilitates judgments of the ingroup (Cadinu \& De Amicis, 1999; Smith et al., 1999). Thus, participants automatically referenced the self when making social judgments.

If we assume that the automatic consultation of self-knowledge during social judgment qualifies as "social projection"—and that the automatic referencing of social knowledge during selfjudgment qualifies as "self-stereotyping" - then the reaction time literature provides strong evidence for both processes. Not all researchers, however, have been eager to grant this assumption. In an influential article, Otten and Epstude (2006) urged that projection and stereotyping be regarded as mechanisms through which representational links are established-that is, as "judgmental processes that underlie (self-ingroup) overlap" (p. 966 [emphasis added]). As such, these researchers characterized social projection and self-stereotyping as tools through which individuals infer self or ingroup knowledge that is not already represented in memory. In keeping with this more restrictive definition of projection and self-stereotyping, Otten and Epstude (2006) replicated Smith and colleagues' (1999) reaction latency tasks, this time limiting analysis to certain subsets of the traits presented to participants. Specifically, the authors retained only traits that were "ill defined" (i.e., rated at the scale midpoint) for the judgmental target but "well-defined" (i.e., given a nonneutral rating) for the presumed anchor of judgment. Hence, when searching for social projection, the authors examined traits that were well-defined for the self but ill defined for the ingroup; conversely, self-stereotyping was sought by examining traits that were well-defined for the ingroup but ill defined for the self. Using this analytic approach, Otten and Epstude (2006) replicated Smith and colleagues' (1999) selfingroup merging effect for judgments of the ingroup, but failed to do so for judgments of the self. The researchers concluded that self-knowledge, but not other-knowledge, anchors judgments when clear-cut information about the target is unavailable.

Otten and Epstude's (2006) findings have frequently been cited as a definitive demonstration of social projection (e.g., Amit, Roccas, \& Meidan, 2010; Becker, 2010; DiDonato, Ullrich, \& Krueger, 2011; Krueger, 2007; Patterson, Bigler, \& Swann, 2010; Peker, Crisp, \& Hogg, 2010; Van Bavel \& Cunningham, 2009) and even something of a knock-out blow to the self-stereotyping explanation for self-other correspondence (Krueger, 2007). Yet, we believe that researchers have too hastily dismissed selfstereotyping. Otten and Epstude (2006), in fact, reached a more nuanced conclusion, speculating that self-stereotyping could be a viable inferential strategy under conditions known to enhance intergroup comparison. Going one step further, we argue that even outside of such contexts, evidence for self-stereotyping may well emerge using a methodology that maximizes statistical power and construct validity. Thus, in the present work, we revisit Otten and Epstude's (2006) paradigm.

In our view, Otten and Epstude's (2006) analysis can be improved in three ways. The first has to do with how the researchers operationalized trait "definedness" versus "ambiguity." Otten and Epstude equate trait definedness with attributional extremity, or the trait ratings' distance from the scale midpoint. Assuming, however, that definedness is meant to tap the degree to which individuals distinctly represent their or others' location on a trait dimension, attributional certainty (i.e., participants' confidence in their trait ratings) may offer a better measure of the construct (see Krosnick, Boninger, Chuang, Berent, \& Carnot, 1993, for a discussion of the various ways in which attitude "strength" may be operationalized). Second, Otten and Epstude applied a datadichotomization strategy common in research using the trait descriptiveness paradigm, in which ordinal ratings of the presumed judgmental anchor (e.g., self-descriptiveness judgments in the context of social projection) are reduced to only two possible values. Unfortunately, this analytic approach inevitably discards information and can give rise to Type I and Type II errors (Maxwell \& Delaney, 1993). Finally, in their tests of social projection and self-stereotyping, Otten and Epstude jettisoned all traits rated as neutral for the judgmental anchor and nonneutral for the target of judgment-resulting, by our reckoning, in the omission of more than half the researchers' observations and thus a great deal of statistical power. In this article, we report a replication of Otten and Epstude's study that avoids these limitations and therefore, we believe, provides a more definitive test of self-stereotyping as a source of self-other correspondence. 


\section{Overview of the Present Research}

The aim of the present research is twofold. First, consistent with our claim that both social projection and self-stereotyping underlie self-other correspondence, we sought direct evidence that selfknowledge influences ingroup judgments and that ingroup knowledge influences self-judgments. To this end, we manipulated participants' self-views (Study 1) and ingroup views (Study 2) on a trait dimension and examined corresponding changes in ingroup judgments and self-judgments, respectively. Ruling out possible alternative explanations for these findings, we showed in Study 3 that social projection and self-stereotyping only occur when the target or source of judgment is an ingroup, but not an outgroup. Second, in a conceptual replication of Otten and Epstude (2006), we sought evidence that both social projection and selfstereotyping are judgmental processes by which people "fill in the gaps" when knowledge of self or ingroup is lacking (Study 4). Together, these studies make the case that, far from being rivals, social projection and self-stereotyping are both powerful explanations for self-other correspondence.

\section{Study 1}

In Study 1, we tested the social projection account of self-other correspondence, in which self-knowledge is used as a basis for judging others. To this end, we manipulated the content of participants' self-concepts and examined subsequent changes in judgments of an ingroup. The self-concept manipulation, adapted from Schwartz and Clore's (1983) mood induction task, had participants write about a number of instances in which they had behaved in either a meticulous or nonmeticulous fashion. Participants then rated an ingroup (i.e., undergraduates at their university) in terms of meticulousness. Meticulousness was chosen as the target trait for two reasons. First, pretesting revealed that our participants tended to see meticulousness as neutral in valence and themselves as average on the trait. We therefore reasoned that meticulousness would be relatively immune to self-presentational effects and amenable to manipulation. Second, Rothbart and Park (1986) found that meticulousness is associated with equally "imaginable" confirming and disconfirming behaviors, suggesting that our manipulation would not be confounded by the ease with which participants could generate meticulous and nonmeticulous behaviors.

\section{Method}

Participants. A sample of 278 undergraduate students at the University of California, Irvine (66.4\% female; $M_{\text {age }}=19.9$, $S D_{\text {age }}=2.0 ; 31.7 \%$ East Asian, $24.8 \%$ European American, $18.7 \%$ Hispanic, $13.7 \%$ South Asian, 6.5\% Filipino, 2.9\% African American, $1.7 \%$ other/unspecified) completed a web-based study for partial course credit.

\section{Manipulation and measures.}

Self-concept manipulation. Participants were randomly assigned to high-self-meticulousness and low-self-meticulousness conditions. All participants were shown a dictionary definition of meticulous. Those in the high-self-meticulousness condition were asked to "describe 9 instances in which they [had] behaved in a meticulous manner"; those in the low-self-meticulous condition recalled nine nonmeticulous behaviors. Participants were encouraged to begin their responses with "I was meticulous when ..." or "I was not meticulous when ..." and typed their answers into text boxes.

Perceived meticulousness of self and ingroup. Self- and ingroup ratings of meticulousness were made using a six-item scale. For self-ratings, the scale consisted of the following items: "The adjective 'meticulous' describes me very well," "When performing a task, I am always meticulous in my approach," "I am always prepared," "I like order," "I am somewhat careless" (reverse coded), and "I am exacting in my work." Ingroup ratings were made on the same scale, with the questions reworded to refer to "students at my university." Participants rated their agreement with each item on a scale ranging from 1 (strongly disagree) to 7 (strongly agree). The scale exhibited adequate internal reliability ( $\alpha=.83$ for self-ratings and .84 for ingroup ratings).

Procedure. After logging on to the study website and providing consent, participants were informed that the study examined the influence of personality on academic success and that the research findings would aid in the creation of a "study habits training program." Participants were then administered the selfconcept manipulation, after which they made meticulousness ratings of the self and ingroup in counterbalanced order. Upon completion of the study, participants were debriefed and thanked.

\section{Results}

Effect of manipulation. To ensure that writing about personal examples of meticulous or nonmeticulous behaviors was effective in changing self-impressions, we tested whether participants in the two conditions differed in their self-ratings of meticulousness. The manipulation was successful in changing participants' self-views, with those in the high-self-meticulousness condition rating themselves as more meticulous $(M=4.73, S D=1.09)$ than those in the low-self-meticulousness condition $(M=4.37, S D=0.95)$, $t(276)=2.91, p=.004, d=.35$.

Evidence for social projection. We next tested whether experimentally induced changes in self-perceived meticulousness were projected to the ingroup. Indeed, we found that participants in the high-self-meticulousness condition rated their peers as more meticulous $(M=4.29, S D=1.12)$ than did those in the low-selfmeticulousness condition $(M=4.05, S D=0.98), t(276)=1.87$, $p=.06, d=.23$. Moreover, consistent with social projection, the manipulation's effect on other ratings was mediated by the changes in self-ratings (see Figure 1): Statistical bootstrapping (Shrout \& Bolger, 2002) revealed a significant indirect effect of the self-concept manipulation on ingroup ratings through self-rated meticulousness $(B=-0.07, S E B=0.04,95 \%$ CI $[-0.16$, $-0.01])^{2}$

\footnotetext{
${ }^{1}$ The latter four items in this scale were taken from the Conscientiousness subscale of John and Srivastava's (1999) Big Five personality trait inventory.

${ }^{2}$ We also tested the reverse mediational pattern, in which perceived ingroup meticulousness mediated the effect of the self-concept manipulation on self-ratings of meticulousness. Bootstrapping revealed no significant indirect effect $(B=-0.04, S E B=0.03,95 \%$ CI $[-0.11,0.02])$.
} 


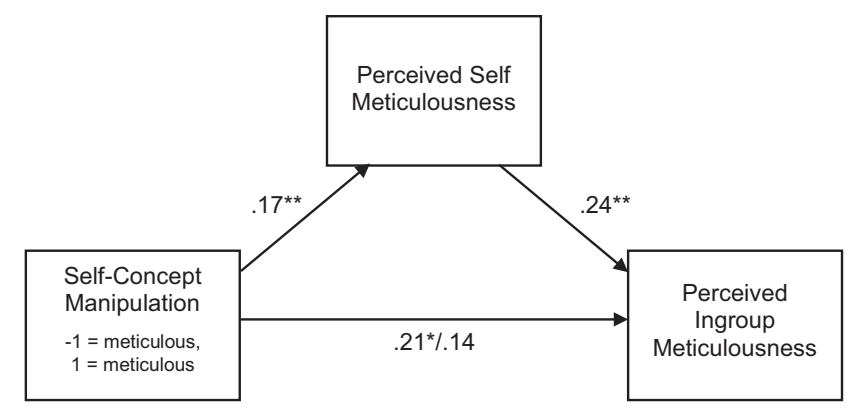

Figure 1. Self-rated meticulousness mediating the effect of self-concept manipulation on ingroup meticulousness ratings in Study 1. Numbers represent betas. ${ }^{*} p<.05 .{ }^{* *} p<.01$.

\section{Discussion}

The results of Study 1 provide direct experimental evidence for social projection. Participants who recalled instances of their own meticulous behavior saw themselves as higher in the trait than those who recalled instances of nonmeticulous behavior. These altered self-perceptions led, in turn, to corresponding changes in perceptions of a salient ingroup (i.e., students at the same university). Thus, as hypothesized, self-knowledge constrains social knowledge in the manner expected if self and ingroup are bidirectionally linked mental representations (Smith et al., 1999; Smith \& Henry, 1996).

\section{Study 2}

Having found evidence for social projection in Study 1, we next tested the self-stereotyping hypothesis-that is, that perceptions of a salient ingroup influence self-perceptions. In Study 2, we manipulated perceptions of the meticulousness of an ingroup (i.e., students at participants' university) and examined resulting changes in participants' perceptions of their own meticulousness.

\section{Method}

Participants. A sample of 327 undergraduate students at the University of California, Irvine $\left(67.7 \%\right.$ female; $M_{\text {age }}=19.9$, $S D_{\text {age }}=1.9 ; 35.3 \%$ East Asian, $23.3 \%$ European American, $17.8 \%$ South Asian, $10.0 \%$ Hispanic, 8.2\% Filipino, 1.2\% African American, $4.2 \%$ other/unspecified) completed a web-based study for partial course credit.

\section{Manipulation and measures.}

Ingroup-stereotype manipulation. Participants read a short description of a fictitious "Transition to UCI project," which purportedly measured the personality traits of 856 incoming freshman from 2006 to 2008. Participants were provided with a dictionary definition of meticulous and randomly assigned to highingroup-meticulousness and low-ingroup-meticulous conditions. Those in the high-ingroup-meticulousness condition were told that a majority of students scored on the high end of the (fictitious) "Trait Meticulousness Scale"; those in the low-ingroupmeticulousness condition were told that most of their fellow students scored low on the scale. These descriptions were accompanied by a histogram conveying either a high mean meticulousness score with a distinct negative skew (high-ingroup-meticulousness condition) or a low mean score with a clear positive skew (lowingroup-meticulousness condition).

Perceived meticulousness of self and ingroup. Self- and ingroup ratings of meticulousness were made using the same sixitem scale as in Study 1. The scale again exhibited adequate internal reliability $(\alpha=.85$ for self-ratings and .84 for ingroup ratings).

Procedure. After reading a short paragraph about the Transition to UCI project, participants were administered the ingroupstereotype manipulation, followed by self- and ingroup ratings of meticulousness in counterbalanced order. Upon completion of the study, participants were debriefed and thanked.

\section{Results}

Manipulation check. The manipulation was effective in changing participants' perceptions of their university peers' meticulousness: Those in the high-ingroup-meticulousness condition rated their peers as more meticulous $(M=4.34, S D=0.94)$ than did those in the low-ingroup-meticulousness condition $(M=3.94$, $S D=1.12), t(325)=-3.55, p<.001, d=.39$.

Evidence for self-stereotyping. We tested whether experimentally induced changes in the perceived meticulousness of the ingroup were introjected to the self. As predicted, participants in the high-ingroup-meticulousness condition rated themselves as more meticulous $(M=4.81, S D=0.94)$ than did participants in the low-ingroup-meticulousness condition $(M=4.54, S D=1.13)$, $t(325)=-2.40, p=.02, d=.26$. Moreover, consistent with self-stereotyping, the manipulation's effect on self-ratings was mediated by the changes in perceptions of the ingroup (see Figure 2): Bootstrapping (Shrout \& Bolger, 2002) revealed a significant indirect effect of the ingroup-stereotype manipulation on self-ratings through meticulousness of the ingroup $(B=-0.06$, $S E B=0.03,95 \%$ CI $[-0.14,-0.01]) .^{3}$

\section{Discussion}

The results of Study 2 provide experimental evidence for selfstereotyping. Participants who were led to believe that their university ingroup was highly meticulous saw themselves as correspondingly higher in the trait than did those who were told that the group was low in meticulousness. Providing further evidence for the self-stereotyping hypothesis, the effect of the ingroupstereotype manipulation on self-perceptions was mediated by perceptions of the ingroup.

Taken together, Studies 1 and 2 offer strong reason to believe that self-knowledge and social knowledge are mutually constraining. However, these findings are also consistent with another explanation. Our manipulations, in addition to changing participants' self-impressions, may have affected self- and ingroup ratings by subtly changing the meaning or salience of the trait being assessed. That is, the manipulation may have raised or lowered the threshold of what qualifies as "meticulous," making it easier or harder for the target of judgment—-self or ingroup—-to qualify as

\footnotetext{
${ }^{3}$ The reverse mediational pattern, in which perceived ingroup meticulousness mediated the effect of the self-concept manipulation on selfratings of meticulousness, was not significant $(B=-0.04, S E B=0.03$, $95 \%$ CI $[-0.10,0.01])$.
} 


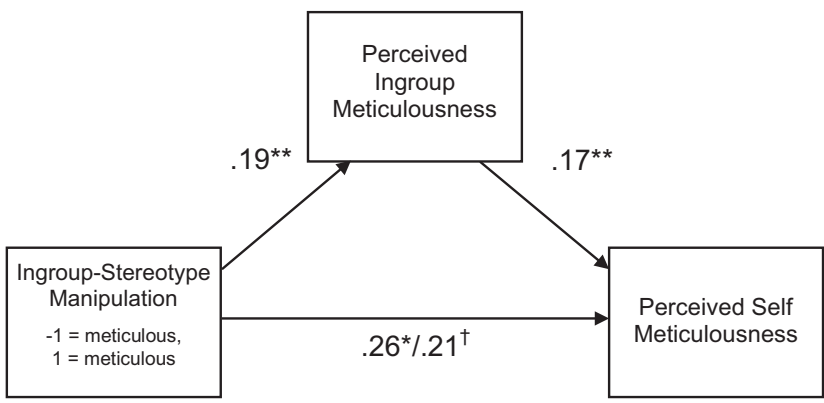

Figure 2. Perceived ingroup meticulousness mediating the effect of ingroup-stereotype manipulation on self-rated meticulousness in Study 2. Numbers represent betas. ${ }^{\dagger} p<.10 .{ }^{*} p<.05 .{ }^{* *} p<.01$.

having the trait. Using a different experimental design, in Study 3 we sought to rule out this semantic alternative explanation.

\section{Study 3}

In Study 3, participants were assigned scores on a novel trait dimension about which they had no prior knowledge or expectations. Crucially, in Study 3 we also manipulated the ingroup versus outgroup status of the target or source of judgment. If the semantic explanation of the Study 1 and Study 2 findings is correct-that is, if our manipulation changed the subjective meaning of the traitthen our self- and group manipulations ought to affect target ratings regardless of the ingroup or outgroup status of the target or source of judgment. However, results in which these effects obtained only in the ingroup condition would provide strong support for genuine social projection and self-stereotyping.

\section{Method}

Participants. A sample of 219 participants (38.5\% female, $M_{\text {age }}=29.6, S D_{\text {age }}=9.1 ; 83.1 \%$ European American, $5.0 \%$ African American, 5.0\% East Asian, 3.2\% Hispanic, 3.7\% other/ unspecified) were recruited via Amazon's Mechanical Turk (MTurk), an online labor market that matches job posters with paid "workers" (see Buhrmester, Kwang, \& Gosling, 2011). All participants reported American citizenship and received $\$ 0.75$ for completing the 5-min online survey.

\section{Manipulation and measures.}

Trait assignment. Participants completed a computerized perceptual task in which they were asked to estimate the number of dots shown briefly (for $300 \mathrm{~ms}$ ) on a series of three screens. This procedure will be familiar to minimal group researchers (e.g., Brewer \& Weber, 1994; Gramzow et al., 2001), and is here used to ascribe participants a minimally informative personality trait. After the task, a brief loading screen was displayed, ostensibly calculating each participant's dot estimation results. Those in the projection condition were told that their scores revealed them to be either an "Overestimator" or "Underestimator." Those in the selfstereotyping condition were told that either an ingroup (other MTurk workers) or an outgroup (construction workers) are mostly Overestimators or Underestimators.

Dependent variable. After receiving the dot estimation task results, participants in the projection condition rated the prevalence (from $0 \%$ to $100 \%$ ) of Overestimators among either the ingroup (other MTurk workers) or an outgroup (construction workers). Participants in the self-stereotyping condition rated the probability (from $0 \%$ to $100 \%$ ) that they themselves are Overestimators.

Procedure. Under the cover story of a "Visual Refraction Study" examining people's patterns of ocular behavior while web browsing, participants completed the dot estimation task. After the task, participants were assigned to one of six conditions and provided corresponding probability estimates, according to a 2 (judgmental anchor: self/social projection vs. group/selfstereotyping) $\times 2$ (group: MTurk workers vs. construction workers) $\times 2$ (task feedback: Overestimator vs. Underestimator) fullfactorial design. At the end of the study, participants provided demographic information, were probed for suspicion, and were debriefed about the manipulation and the true purpose of the study.

\section{Results}

These data were analyzed by regressing Overestimator prevalence ratings onto judgmental anchor $(-1=$ self, $1=$ group $)$, group $(-1=$ MTurk workers, $1=$ construction workers $)$, task feedback $(-1=$ Underestimator, $1=$ Overestimator), as well as all two- and three-way interactions involving these variables.

Evidence for social projection and self-stereotyping. We tested whether an experimentally manipulated minimal trait would be projected to the group or introjected to the self. Although the task feedback main effect was nonsignificant, we observed a significant Group $\times$ Task Feedback interaction $(B=-4.28, S E$ $B=1.50, z=-2.84, p=.004)$, suggesting that the effect of the trait manipulation on prevalence/probability estimates varied depending on whether the relevant group was an ingroup (i.e., MTurk workers) or an outgroup (i.e., construction workers). The pattern of results within the self-anchor (social projection) and ingroup anchor (self-stereotyping) conditions is depicted in Figures 3 and 4, respectively. Simple slope analysis revealed that, when told that most MTurk workers are Overestimators, participants deemed themselves probable Overestimators as well ( $B=16.34, S E B=$ $5.90, z=2.77, p=.006)$; likewise, when told that they themselves were Overestimators, participants inferred that MTurk workers

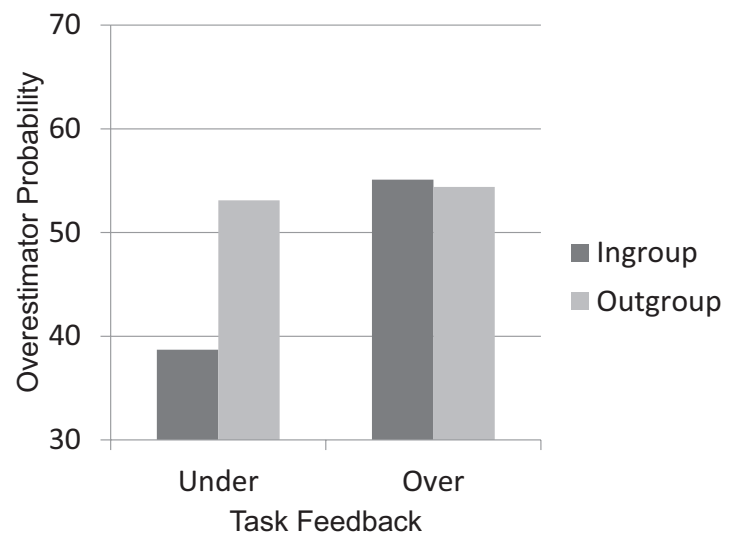

Figure 3. Self-stereotyping: Probability estimates of self being an Overestimator, as a function of group designation and level of manipulation in Study 3. 


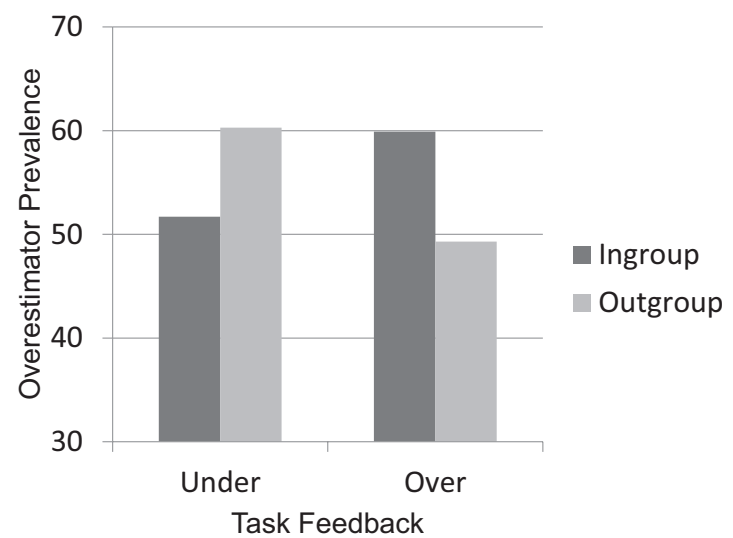

Figure 4. Social projection: Prevalence estimates of Overestimators in group, as a function of group designation and level of manipulation in Study 3.

also tend to be Overestimators $(B=8.16, S E B=3.43, z=2.38$, $p=.017)$. In contrast, participants neither self-stereotyped from $(B=1.28, S E B=7.03, z=.65, p=.86)$ nor projected to $(B=$ $-11.08, S E B=7.02, z=-1.58, p=.11$ ) the outgroup (i.e., construction workers). The observed lack of a Judgment Anchor $\times$ Task Feedback interaction $(B=-5.13, S E B=2.97, z=-1.73$, $p=.08)$, or Judgment Anchor $\times$ Task Feedback $\times$ Group interaction $(B=-.52, S E B=1.54, z=-.34, p=.73)$, suggests that the projection and self-stereotyping effects were equal in magnitude.

\section{Discussion}

Study 3 replicates the findings from Studies 1 and 2 in a noncollege student population, using a different trait and a different ingroup membership. More importantly, the absence of projection or self-stereotyping in the outgroup (i.e., construction worker) condition rules out a semantic alternative explanation for the results of Studies 1 and 2. If our manipulation succeeded only in changing the subjective definition of a trait, then one would expect an identical pattern of results regardless of the ingroup or outgroup status of the source or target of judgment.

Across three studies, we have shown that judgments of the self are not made in isolation of ingroup perceptions, nor social judgments in isolation of the self. Thus, the present studies suggest that social projection and self-stereotyping may represent equally valid explanations for perceived self-other correspondence. Notably, participants in Study 3 readily projected and introjected a novel trait dimension of which they had little or no prior knowledge. This pattern thus provides evidence for social projection and self-stereotyping in keeping with Otten and Epstude's (2006) definition of these processes as judgmental strategies when self- or ingroup knowledge is lacking. We next attempt to reconcile these findings directly with Otten and Epstude's reaction time data, which suggest that social projection-but not self-stereotyping-underlie self-other correspondence.

\section{Study 4}

\section{Overview}

In Study 4, we revisit Otten and Epstude's (2006) analysis and findings. These authors define social projection and selfstereotyping as judgmental strategies that "fill in the gaps" when knowledge of the self or ingroup is absent or weakly represented in memory. So construed, social projection and self-stereotyping are best assessed by examining traits that are more strongly defined for the presumed judgmental anchor than for the judgmental target. When Otten and Epstude's participants made ingroupdescriptiveness judgments for traits deemed well-defined for the self (i.e., the anchor) but ill defined for the target (i.e., the ingroup), a distinct pattern of self-ingroup merging (Smith \& Henry, 1996) was observed. Because self-ingroup merging arose when the anchor was better defined than the target, the authors interpreted these results as clear evidence for self-projection as a knowledgebuilding process. In contrast, because no merging effect was obtained when participants made ingroup-descriptiveness judgments of traits deemed better defined for the ingroup (i.e., anchor) than for the self (i.e., target), the researchers concluded that selfstereotyping is not a significant source of new self-knowledge.

Although we find the logic of Otten and Epstude's (2006) analysis compelling, their conclusions do not cohere with the results of our Study 3. In this experiment, participants appeared to engage in both social projection and self-stereotyping-even when lacking prior knowledge of the target's standing on the trait in question (i.e., Overestimator vs. Underestimator). In order to reconcile these results, we revisit Otten and Epstude's paradigm. In attempting to replicate these authors' findings, we sought to improve on the original procedure and analyses in order to afford a more definitive test of social projection and self-stereotyping processes. We next enumerate our alterations to Otten and Epstude's design and analyses.

\section{Retain All Traits}

Otten and Epstude (2006) tested for social projection and selfstereotyping by analyzing only reaction latencies for traits that had previously received extreme descriptiveness ratings for the anchor and middling ratings for the target. Thus, social projection was assessed after discarding all traits for which self-ratings occupied the scale midpoint and ingroup ratings diverged from the midpoint. Similarly, self-stereotyping was assessed after discarding traits for which ingroup ratings occupied the scale midpoint and self-ratings diverged from the midpoint. Although the authors do not report how many observations were lost in each of these analyses, it is likely that many cases-and thus much statistical power-were lost. We sought to avoid screening out traits and instead examined both social projection and self-stereotyping by fitting a single statistical model to the entirety of the data.

\section{Operationalize Trait "Definedness" as Certainty (Not Extremity)}

Otten and Epstude (2006) operationalized trait definedness- the degree of clarity with which individuals represent their standing on a trait dimension-in terms of judgmental extremity. Thus, ill 
defined (or "ambiguous") traits were those that occupied the midpoint of a 7-point scale anchored by very untypical (of me) to very typical (of me). In light of the fact that attitudes can be characterized along a number of strength-related dimensions (Krosnick et al., 1993), we suspected that definedness might be best tapped not by extremity, but by certainty - that is, the level of confidence with which an individual makes an attribution. Indeed, operationalizing trait definedness as extremity ignores the very real possibility of having a well-defined perception of the self or other as "medium" (i.e., near the midpoint) on a given trait dimension. We therefore used confidence ratings, rather than extremity, as our index of trait definedness.

\section{Avoid Dichotomization}

In analyzing reaction latency data from the trait descriptiveness paradigm, studies have tended to dichotomize at least one predictor variable (e.g., Aron, Aron, \& Smollan, 1992; Aron, Aron, Tudor, \& Nelson, 1991; Smith et al., 1999; Smith \& Henry, 1996; Tropp $\&$ Wright, 2001). For instance, when reaction times are elicited for ingroup traits, researchers frequently dichotomize participants' ratings of the self. Although useful for illustrative purposes, this approach is statistically nonoptimal. Simulation studies have shown that dichotomizing ordinal or continuous predictors inevitably discards information and can yield Type I and Type II errors (Maxwell \& Delaney, 1993; Vargha, Rudas, Delaney, \& Maxwell, 1996). Thus, in our analyses, we retained ratings of self- and ingroup traits in their original, ordinal form. In intuitive terms, this allows for degrees of match between self and ingroup; for example, traits deemed descriptive of the self in the reaction time portion of the task would match a trait rated 2 for the ingroup better than a trait rated 1 .

\section{Temporal Separation of Study Phases}

In the typical trait descriptiveness study, participants complete the reaction latency portion of the procedure immediately after making ordinal ratings of traits' self- and ingroup descriptiveness. This raises the possibility that individuals' memory of their initial (ordinal) ratings could influence their timed (dichotomous) judgments in the latter phase of the study, perhaps exaggerating effects of trait matches and mismatches on reaction latencies. To minimize this possibility, participants in the present study completed the two study phases on separate days.

\section{Method}

Participants. A sample of 100 undergraduates at the University of California, Irvine $\left(M_{\text {age }}=20.4, S D_{\text {age }}=4.2 ; 75.8 \%\right.$ female; $28.1 \%$ East Asian, 25.8\% European American, $18.7 \%$ South Asian, 15.6\% Hispanic, 10.2\% Filipino, 0.8\% African American, $0.8 \%$ other/unspecified) completed a web-based survey and laboratory task for partial course credit.

Procedure and materials. The study consisted of two phases: a web-based survey in which participants provided self- and ingroup descriptiveness judgments of 90 traits, as well as confidence ratings for each of these judgments, and a laboratory session in which participants made dichotomous self- and ingroup descriptiveness judgments for the 90 traits. The web-based and laboratory sessions were spaced by at least $24 \mathrm{hr}$.
Online survey. Upon signing up for the study, participants scheduled a laboratory session and were e-mailed a link to the web-based portion of the study. After providing consent and demographic information, participants were twice presented with a randomly ordered series of 90 traits previously used by Aron and colleagues (1991). On one presentation, participants rated themselves; on the other, they rated their gender ingroup. The order of self and gender questions was counterbalanced. For the selfratings, participants reported the degree to which each trait described them on a 5-point scale $(1=$ not at all descriptive of $M E$; $5=$ very descriptive of $M E$ ), followed by their confidence in that rating on a 3 -point scale $(1=$ low confidence; $2=$ neutral confidence; 3 = high confidence). Ingroup ratings were made in similar fashion, with "ME" replaced by "MEN" or "WOMEN" as appropriate.

Laboratory session. After arriving at the laboratory, participants were seated at a computer station and asked to complete two reaction latency tasks. In these tasks, participants judged whether each of the 90 traits previously rated in the online session described the self or gender ingroup. Rating of the self and gender ingroup were blocked and presented in counterbalanced order. In each block, the 90 traits appeared in randomized sequence in the center of the screen. Participants were instructed to press the $I$ key to indicate that a trait described the self (ingroup) and the $E$ key to indicate that a trait did not describe the self (ingroup) and to be as fast and accurate as possible on all trials. Reaction latencies were recorded for all responses.

\section{Results}

None of the results reported below were moderated by participant gender, the order of tasks, or their interactions with our predictors of interest. We therefore collapsed the data across these dimensions in the analyses reported below.

Data preparation. Reaction latency distributions tend to exhibit a positive skew that violates common statistical assumptions (Ratcliff, 1993). To correct for this, we followed Otten and Epstude's (2006) data normalization procedure, deleting latencies more than two standard deviations from the grand mean $(4.06 \%$ of cases) and log-transforming those that remained.

Computation of the relative anchor certainty index. Otten and Epstude (2006) argued that social projection and selfstereotyping are best assessed when the presumed judgmental anchor is well-defined and the judgmental target is ill defined. We assessed the degree to which this is the case by creating a difference score, subtracting each trait's definedness (i.e., certainty) as the target from its certainty as the anchor. We term this index relative anchor certainty. Thus, in the case of social projection, relative anchor certainty represents traits' definedness as self-descriptors minus their definedness as ingroup descriptors. Conversely, self-stereotyping casts the ingroup as the anchor and the self as the target; in this case, relative anchor certainty is computed by subtracting each trait's ingroup definedness from its self-definedness. In short, high levels of relative anchor certainty mark the context in which, according to Otten and Epstude, self-ingroup merging must occur in order 
to qualify as instances of social projection and selfstereotyping.

Summary of design. Because participants made timed judgments both of traits' self- and ingroup descriptiveness, our design included a within-subject factor varying judgmental anchor. The anchor factor consisted of two levels: (a) the self anchor condition, corresponding to social projection, wherein timed judgments were made of the ingroup; and (b) the ingroup anchor condition, corresponding to self-stereotyping, in which timed ratings were made of the self. The meanings of the remaining variables-relative anchor certainty, anchor judgment, and target judgment—vary by anchor condition as appropriate.

Analyses. Because the data were nested, with 180 reaction latencies for each participant (i.e., self- and ingroup latencies for each of 90 traits), effects were tested using multilevel modeling in hierarchical linear modeling (HLM) 6 (Raudenbush, Bryk, Cheong, \& Congdon, 2004). We specified a Level 1 (within-person) model in which log-transformed reaction latencies were regressed onto valence $(-1=$ negative, $0=$ neutral, $1=$ positive); judgmental anchor $(-1=$ self, $1=$ ingroup); relative anchor certainty; anchor descriptiveness (i.e., ordinal ratings assessed at pretest); target descriptiveness ( -1 = "no", 1 = "yes"), as well as all two-, three-, four-, and five-way interactions between these variables. Level 2 equations were then created to represent the fixed effects of each Level 1 predictor. Only the intercept was allowed to vary randomly, yielding a random-intercept model.

Table 1 reports results of this analysis. Because the model involves a great many terms, we report the results without valence and its interactions; the reported effects, however, control for valence as a covariate. As an aid to interpretation, we note in Table 1 that the Anchor Descriptiveness $\times$ Target Descriptiveness interaction may be taken to reflect a single quantity - that is, the magnitude of Smith and Henry's (1996) basic self-ingroup merging effect, in which participants judge the target descriptiveness of traits that match the self and ingroup more quickly than traits seen to characterize only the self or the ingroup. As can be seen in Table 1, the self-ingroup merging effect (i.e., Anchor Descriptiveness $\times$ Target Descriptiveness interaction) was replicated $(B=0.020, S E B=0.003)$, $t(16700)=-7.76, p=9.29 \times 10^{-15}$. However, judgmental anchor did not significantly moderate the merging effect $(B=$ $-0.003, S E=0.003), t(16677)(t=-0.99, p=.32)$, indicating that the merging effect was similar in magnitude whether the self or the ingroup was the target of judgment. Moreover, relative anchor certainty (i.e., the extent to which traits were better defined for the anchor than for the target) failed to moderate the merging effect $(B=-0.001, S E B=0.003)$, $t(16682)=-0.22, p=.82$, suggesting that the anchor guided target judgments irrespective of anchor and target traits' relative definedness. Finally, the crucial interaction between anchor, relative anchor certainty, and the merging effect was nonsignificant $(B=0.001, S E B=0.003), t(16680)=0.33$, $p=.74$, indicating that the merging effect remained constant across levels of relative anchor certainty for both social projection and self-stereotyping. The merging effects for selfstereotyping and social projection are plotted in Figures 5 and 6 , respectively.

\section{Discussion}

The results of Study 4 suggest that social projection and self-stereotyping both function as judgmental strategies by which individuals infer "missing" information about the ingroup and the self (Otten \& Epstude, 2006). The absence of an effect of relative anchor certainty indicates that participants consulted the ingroup stereotype when judging the self-regardless of the relative clarity with which individuals represented the ingroup's traits. Likewise, participants anchored ingroup judgments on self-knowledge irrespective of the relative clarity of individuals' self-representations. These findings suggest that egocentric and protocentric learning processes both contribute to the merging of self- and ingroup representations in memory - and, by extension, to the overperception of similarity between self and others (i.e., self-other correspondence).

Table 1

Results of Multilevel Model Predicting Log-Transformed Target Judgment Latencies in Study 4

\begin{tabular}{|c|c|c|c|c|c|}
\hline Effect & $B$ & $S E B$ & $d f$ & $t$ & Exact $p$ \\
\hline Intercept & $6.947^{* * * *}$ & 0.021 & 102 & 323.83 & $7.81 \times 10^{-155}$ \\
\hline Anchor & $-0.013^{* *}$ & 0.004 & 16676 & -3.16 & $1.57 \times 10^{-03}$ \\
\hline Relative anchor certainty (Certainty) & $-0.023^{* * *}$ & 0.005 & 16679 & -4.38 & $1.19 \times 10^{-05}$ \\
\hline Anchor descriptiveness (AD) & -0.004 & 0.003 & 16702 & -1.45 & 0.15 \\
\hline Target descriptiveness (TD) & $-0.061^{* * *}$ & 0.004 & 16687 & -14.68 & $1.63 \times 10^{-48}$ \\
\hline Anchor $\times$ Certainty & $0.010^{\dagger}$ & 0.006 & 16756 & 1.78 & 0.08 \\
\hline Anchor $\times \mathrm{AD}$ & 0.001 & 0.003 & 16687 & 0.44 & 0.66 \\
\hline Anchor $\times$ TD & $0.012^{* *}$ & 0.004 & 16683 & 2.88 & $4.00 \times 10^{-03}$ \\
\hline Certainty $\times \mathrm{AD}$ & 0.005 & 0.003 & 16684 & 1.40 & 0.16 \\
\hline Certainty $\times \mathrm{TD}$ & $0.032^{* * * *}$ & 0.005 & 16696 & 6.03 & $1.67 \times 10^{-09}$ \\
\hline $\mathrm{AD} \times \mathrm{TD}($ Merging Effect) & $-0.020^{* * * *}$ & 0.003 & 16700 & -7.76 & $9.29 \times 10^{-15}$ \\
\hline Anchor $\times$ Certainty $\times \mathrm{AD}$ & 0.008 & 0.003 & 16685 & 2.23 & 0.03 \\
\hline Anchor $\times$ Certainty $\times$ TD & $-0.028^{* * * *}$ & 0.005 & 16694 & -5.22 & $1.77 \times 10^{-07}$ \\
\hline Anchor $\times$ Merging Effect & -0.003 & 0.003 & 16677 & -0.99 & 0.32 \\
\hline Certainty $\times$ Merging Effect & -0.001 & 0.003 & 16682 & -0.22 & 0.82 \\
\hline Anchor $\times$ Certainty $\times$ Merging Effect & 0.001 & 0.003 & 16680 & 0.33 & 0.74 \\
\hline
\end{tabular}

${ }^{\dagger} p<.1 . \quad{ }^{* * *} p<.01 . \quad{ }^{* * *} p<.001$. 


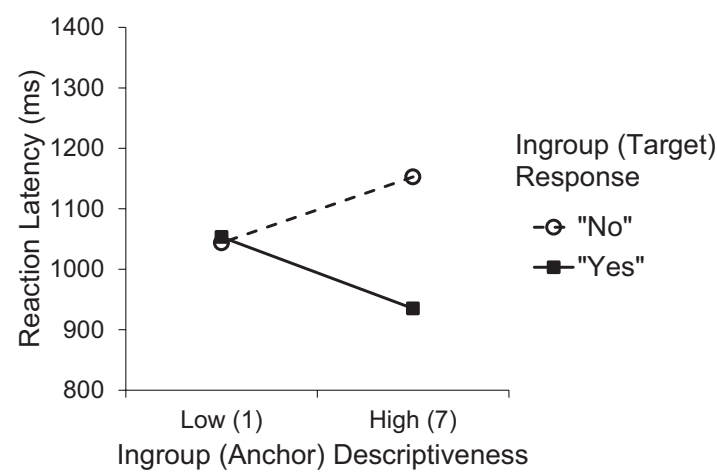

Figure 5. Social projection: Reaction latencies as a function of traits' anchor (self) and target (ingroup) descriptiveness in Study 4.

The present results run counter to those of Otten and Epstude (2006). ${ }^{4}$ These researchers argue that, in the context of Smith and Henry's (1996) reaction time paradigm, social projection and self-stereotyping (qua learning processes) can only be validly diagnosed when the anchor of judgment is more clearly defined than the target. In such cases, Otten and Epstude replicated the Smith and Henry's merging effect when the self was the anchor and the ingroup the target (social projection), but not when the ingroup was the anchor and the self was the target (selfstereotyping). In our Study 4, however, we found no evidence to suggest that relative anchor certainty moderated the merging effect, either for projection or for self-stereotyping. This implies that merging was equally pronounced for projection and selfstereotyping in the context that Otten and Epstude specifically identify as diagnostic of these processes.

This inconsistency may stem in part from methodological differences between the studies. First, whereas Otten and Epstude (2006) omitted a large number of observations from their analyses, we maximized statistical power by retaining all of our data. Second, whereas Otten and Epstude used attributional extremity as the index of trait definedness, we operationalized this construct as the confidence with which participants attributed a trait to the self or ingroup. Third, whereas Otten and Epstude dichotomized the measures of traits' descriptiveness of the presumed judgmental anchor, we kept these variables in their original, ordinal form. In our view, these methodological improvements shift the onus back onto researchers who would suggest that only egocentric processes contribute significantly to self-ingroup merging and self-other correspondence.

\section{General Discussion}

The results of four studies converge to suggest that both social projection and self-stereotyping processes contribute to self-other correspondence, individuals' well-documented tendency to perceive themselves as similar to others. Consistent with connectionist and constraint-satisfaction models of self- and ingroup representations (Balcetis \& Dunning, 2005; Read et al., 1997; Smith et al., 1999), Studies 1 and 2 suggest that the self-concept and social knowledge causally constrain one another: Participants whose self-views were manipulated displayed corresponding changes in judgments of a salient ingroup (Study 1); conversely, manipulating ingroup perceptions changed how participants saw themselves (Study 2). Study 3 rules out a semantic alternative explanation of these results and demonstrates that group membership moderated social projection and self-stereotyping, such that participants only projected to or self-stereotyped from the ingroup. Finally, Study 4 suggests that social projection and self-stereotyping are both important sources of self-other merging. When participants were unsure whether or not a trait described themselves or their gender ingroup, they anchored ingroup judgments on self-knowledge (social projection) and self-judgments on ingroup knowledge (selfstereotyping). Taken together, our studies imply that social projection and self-stereotyping both help explain the correspondence between self- and other judgments.

\section{Underlying Mechanisms for Social Projection and Self-Stereotyping}

Future research is needed to address whether there is a single, general model of inference that can accommodate both social projection and self-stereotyping. One important question for any such model to answer is whether social projection and selfstereotyping judgments are more "elaborated" and attributional, or more automatic and associative. Associative processes are ones in which cognitive representations become linked through their simultaneous activation alone (e.g., the spontaneous trait transference effect; Carlston \& Skowronski, 2005). In contrast, attributional processes involve relatively deeper and more elaborated mental processing, such as reference to mental schemata and judgmental rules (Carlston \& Skowronski, 2005).

Recent theorizing suggests that interpersonal perception, even when implicit, often involves some amount of elaborated processing. Models of social projection posit automatic processes that link social representations to the egocentric anchor (e.g., Kawada, Oettingen, Gollwitzer, \& Bargh, 2004; Krueger, 2007; McCulloch, Ferguson, Kawada, \& Bargh, 2008), which might be taken to suggest shallow processing. However, recent work suggesting that even implicit priming effects (which are usually taken to represent highly automatic associative links) may involve attributional processing (Loersch \& Payne, 2011) hints that projection and stereotyping might involve a similarly elaborated component. Moreover, findings that accuracy incentives (Epley et al., 2004), perceived similarity (Ames, 2004b), and self-protective motivations (Sherman \& Kim, 2005) moderate social projection suggest that this process involves some amount of elaboration.

\footnotetext{
${ }^{4}$ We conducted additional analyses using Otten and Epstude's (2006) guidelines-dichotomizing anchor ratings and limiting the analysis only to traits for which the target ratings were at the scale midpoint but anchor ratings were at the extremes-but were unable to produce evidence of self-other merging as social projection. When ingroup ratings occupied the scale midpoint (i.e., ill defined) and self-ratings diverged from the midpoint (i.e., well-defined), the Anchor Descriptiveness $\times$ Target Descriptiveness interaction was a nonsignificant factor $(B=.008, S E B=.021, p=.72)$. When the analogous procedure was used, there was also no significant effect of merging as self-stereotyping $(B=-.033, S E B=.018, p=.066)$ Nevertheless, using Smith and collaborators' (Smith et al., 1999; Smith \& Henry, 1996) original procedure-dichotomizing the anchor ratings and limiting the analysis only to the well-defined traits for both the anchor and target-we were able to replicate the merging effects for both social projection $(B=-.055, S E B=.009, p<.001)$ and self-stereotyping $(B=$ .057$, SE $B=.007, p<.001)$.
} 


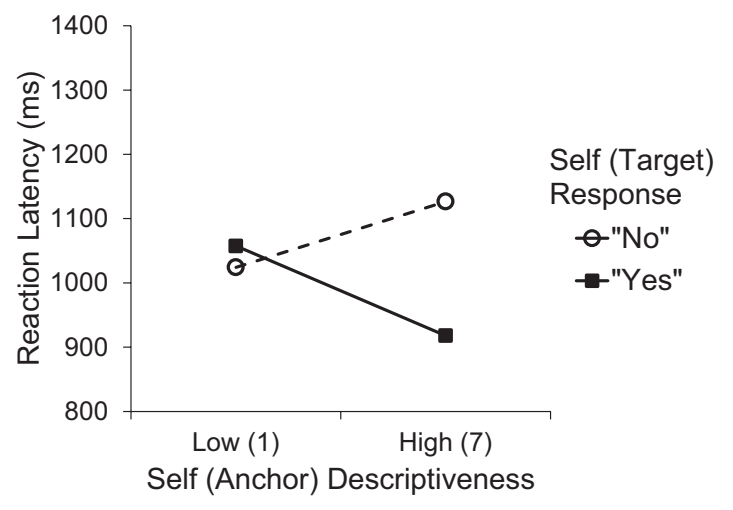

Figure 6. Self-stereotyping: Reaction latencies as a function of traits' anchor (ingroup) and target (self) descriptiveness in Study 4.

Traditional models of self-stereotyping (Turner et al., 1987) have tended to emphasize deliberative thought processes and explicit self-reports. Moreover, although recent findings suggest that self-stereotyping occurs at an implicit level (Cadinu \& Galdi, 2012; Devos, 2006; McCall \& Dasgupta, 2007), as Leorsch and Payne (2011) observe, automaticity does not rule out the operation of more elaborated attributional processing.

In light of findings such as those just described, it strikes us as likely that an integrated model of social projection and selfstereotyping will be at least partly attributional, rather than purely associative, in nature. The present studies, however, do not speak directly to this issue. ${ }^{5}$

\section{Relative Strengths of Social Projection and Self-Stereotyping Effects}

In Studies 3 and 4, judgmental anchor (self vs. ingroup) failed to moderate self-other merging effects. These results, however, do not necessarily indicate that projection and self-stereotyping are equally important contributors to self-other merging. First, failure to reject a null hypothesis does not necessarily mean that difference does not exist. Second, the manipulations used to manipulate self- and ingroup views in Studies 1, 2, and 3 were not directly analogous. Given this methodological asymmetry, comparison between the relative strengths projection and self-stereotyping effects is unwarranted. Finally, even if projection and self-stereotyping produce empirically equal effects, there are still reasons to believe that projection may be the more powerful process. Dawes (1990) showed that inferences made from data (i.e., self) to the category from which they are sampled (i.e., ingroup) have smaller error variances than inferences made from categories to data (i.e., selfstereotyping). Thus, projection effects should be more difficult to demonstrate statistically than self-stereotyping effects of equal magnitude. Despite these caveats, the present findings suggest that both processes occur, and theorists should take care in explaining self-other correspondence effects as resulting from either projection or self-stereotyping to the exclusion of the other process.

\section{Projection, Self-Stereotyping, and Ingroup Favoritism}

Another important aspect of the projection-stereotyping debate extends beyond judgmental and representational processes and involves the motivational basis behind ingroup favoritism. Both social identity theory (Tajfel \& Turner, 1986) and selfcategorization theory (Turner et al., 1987) posit that, because one's social identity forms an important part of the self-concept, ingroup favoritism is a way to bolster or enhance self-esteem. However, the projection-based explanation of ingroup favoritism (Cadinu \& Rothbart, 1996; Clement \& Krueger, 2000; Gramzow \& Gaertner, 2005; Gramzow et al., 2001; Otten, 2004) suggests instead that bias is rooted in an automatic association between (typically favorable) self-evaluations and ingroup evaluations. The present findings do not speak directly to either account, but we would speculate that the bidirectional relationship we observed between self- and ingroup judgments may also underlie ingroup favoritism.

\section{Conclusion}

We hope that the present findings encourage reconciliation between parties to the ongoing debate between egocentric and protocentric accounts of person perception (Karniol, 2003; Krueger, 2003; Mussweiler, 2003; Sedikides, 2003). It is our view that theorists in either camp would be hard-pressed to deny the validity of the opposing account - and, echoing a view that has been expressed elsewhere (Balcetis \& Dunning, 2005; Latrofa, Vaes, Cadinu, \& Carnaghi, 2010; Otten, 2005), that investigators should focus instead on identifying moderators of egocentric and protocentric processes. To this end, future research might adapt the procedure used in Study 4 to investigate various individual differences or situational contexts that incline individuals to exhibit more egocentric or protocentric social judgments. In conclusion, we believe that social projection and self-stereotyping need not be mutually exclusive and that a model synthesizing these two accounts would be more fitting than either account alone.

\footnotetext{
${ }^{5}$ That said, certain effects of trait valence in Study 4 could be interpreted as reflecting self-serving bias, which in turn may hint at underlying attributional processes. Presumably, self-serving motivations would have different effects on projection and self-stereotyping. One might be hesitant to introject negative traits of the ingroup, and accordingly self-stereotyping effects would be weaker for negative traits. Conversely, the threat of having negative traits might be ameliorated if they are also shared by the ingroup, making projection stronger for negative traits. Trends involving valence in Study 4 were consistent with this motivated attributional pattern. The basic merging effect (Anchor Descriptiveness $\times$ Target Descriptiveness, $B=-.020$ ) was weaker for negative traits (Valence $\times$ Anchor Descriptiveness $\times$ Target Descriptiveness, $B=-.01$ ), and this pattern was stronger for self-stereotyping than for projection (Anchor $\times$ Valence $\times$ Anchor Descriptiveness $\times$ Target Descriptiveness, $B=.00054, p=.064$ with robust $S E$ ). It seems, then, that people are more willing to project than to introject negative traits.
}

\section{References}

Ames, D. R. (2004a). Inside the mind reader's tool kit: Projection and stereotyping in mental state inference. Journal of Personality and Social Psychology, 87, 340-353. doi:10.1037/0022-3514.87.3.340

Ames, D. R. (2004b). Strategies for social inference: A similarity contingency model of projection and stereotyping in attribute prevalence estimates. Journal of Personality and Social Psychology, 87, 573-585. doi:10.1037/0022-3514.87.5.573

Amit, A., Roccas, S., \& Meidan, M. (2010). A group just like me: The moderating role of conservation values on social projection. European Journal of Social Psychology, 40, 931-945. doi:10.1002/ejsp.658 
Aron, A., Aron, E. N., \& Smollan, D. (1992). Inclusion of Other in the Self Scale and the structure of interpersonal closeness. Journal of Personality and Social Psychology, 63, 596-612. doi:10.1037/0022-3514.63.4.596

Aron, A., Aron, E. N., Tudor, M., \& Nelson, G. (1991). Close relationships as including other in the self. Journal of Personality and Social Psychology, 60, 241-253. doi:10.1037/0022-3514.60.2.241

Balcetis, E., \& Dunning, D. A. (2005). Judging for two: Some connectionist proposals for how the self informs and constrains social judgment. In M. D. Alicke, D. A. Dunning, \& J. I. Krueger (Eds.), The self in social judgment (pp. 181-211). New York, NY: Psychology Press.

Bargh, J. A., Chen, M., \& Burrows, L. (1996). Automaticity of social behavior: Direct effects of trait construct and stereotype activation on action. Journal of Personality and Social Psychology, 71, 230-244. doi:10.1037/0022-3514.71.2.230

Becker, J. C. (2010). Why do women endorse hostile and benevolent sexism? The role of salient female subtypes and internalization of sexist contents. Sex Roles, 62, 453-467. doi:10.1007/s11199-009-9707-4

Birch, S. A. J., \& Bloom, P. (2007). The curse of knowledge in reasoning about false beliefs. Psychological Science, 18, 382-386. doi:10.1111/j .1467-9280.2007.01909.x

Brewer, M. B., \& Weber, J. G. (1994). Self-evaluation effects of interpersonal versus intergroup social comparison. Journal of Personality and Social Psychology, 66, 268-275. doi:10.1037/0022-3514.66.2.268

Buhrmester, M., Kwang, T., \& Gosling, S. D. (2011). Amazon's Mechanical Turk: A new source of inexpensive, yet high-quality, data? Perspectives on Psychological Science, 6, 3-5. doi:10.1177/ 1745691610393980

Cadinu, M. R., \& De Amicis, L. (1999). The relationship between the self and the ingroup: When having a common conception helps. Swiss Journal of Psychology/Schweizerische Zeitschrift für Psychologie/Revue Suisse de Psychologie, 58, 226-232. doi:10.1024//1421-0185.58.4.226

Cadinu, M., \& Galdi, S. (2012). Gender differences in implicit gender self-categorization lead to stronger gender self-stereotyping by women than by men. European Journal of Social Psychology, 42, 546-551. doi:10.1002/ejsp.1881

Cadinu, M. R., \& Rothbart, M. (1996). Self-anchoring and differentiation processes in the minimal group setting. Journal of Personality and Social Psychology, 70, 661-677. doi:10.1037/0022-3514.70.4.661

Carlston, D. E., \& Skowronski, J. J. (2005). Linking versus thinking: Evidence for the different associative and attributional bases of spontaneous trait transference and spontaneous trait inference. Journal of Personality and Social Psychology, 89, 884-898. doi:10.1037/00223514.89.6.884

Cialdini, R. B., \& Trost, M. R. (1998). Social influence: Social norms, conformity and compliance. In D. T. Gilbert, S. T. Fiske, \& G. Lindzey (Eds.), The handbook of social psychology (4th ed., Vols. 1 and 2, pp. 151-192). New York, NY: McGraw-Hill.

Clement, R. W., \& Krueger, J. I. (2000). The primacy of self-referent information in perceptions of social consensus. British Journal of Social Psychology, 39, 279-299. doi:10.1348/014466600164471

Critcher, C. R., \& Dunning, D. (2009). Egocentric pattern projection: How implicit personality theories recapitulate the geography of the self. Journal of Personality and Social Psychology, 97, 1-16. doi:10.1037/ a0015670

Dawes, R. M. (1990). The potential nonfalsity of the false consensus effect. In R. M. Hogarth (Ed.), Insights in decision making: A tribute to Hillel J. Einhorn (pp. 179-199). Chicago, IL: University of Chicago Press.

Devos, T. (2006). Implicit bicultural identity among Mexican American and Asian American college students. Cultural Diversity and Ethnic Minority Psychology, 12, 381-402. doi:10.1037/1099-9809.12.3.381

DiDonato, T. E., Ullrich, J., \& Krueger, J. I. (2011). Social perception as induction and inference: An integrative model of intergroup differentiation, ingroup favoritism, and differential accuracy. Journal of Personality and Social Psychology, 100, 66-83. doi:10.1037/a0021051
Dunning, D. (2003). The relation of self to social perception. R. Leary \& J. P. Tangney (Eds.), Handbook of self and identity (pp. 421-441). New York, NY: Guilford Press.

Epley, N., Keysar, B., Van Boven, L., \& Gilovich, T. (2004). Perspective taking as egocentric anchoring and adjustment. Journal of Personality and Social Psychology, 87, 327-339. doi:10.1037/0022-3514.87.3.327

Festinger, L. (1954). A theory of social comparison processes. Human Relations, 7, 117-140. doi:10.1177/001872675400700202

Gaertner, L., Sedikides, C., Vevea, J. L., \& Iuzzini, J. (2002). The "I," the "we," and the "when": A meta-analysis of motivational primacy in self-definition. Journal of Personality and Social Psychology, 83, 574591. doi:10.1037/0022-3514.83.3.574

Galinsky, A. D., Wang, C. S., \& Ku, G. (2008). Perspective-takers behave more stereotypically. Journal of Personality and Social Psychology, 95 404-419. doi:10.1037/0022-3514.95.2.404

Gino, F., Ayal, S., \& Ariely, D. (2009). Contagion and differentiation in unethical behavior: The effect of one bad apple on the barrel. Psychological Science, 20, 393-398. doi:10.1111/j.1467-9280.2009.02306.x

Gordon, R. M. (1986). Folk psychology as simulation. Mind and Language, 1, 158-171. doi:10.1111/j.1468-0017.1986.tb00324.x

Gramzow, R. H., \& Gaertner, L. (2005). Self-esteem and favoritism toward novel in-groups: The self as an evaluative base. Journal of Personality and Social Psychology, 88, 801-815. doi:10.1037/0022-3514.88.5.801

Gramzow, R. H., Gaertner, L., \& Sedikides, C. (2001). Memory for in-group and out-group information in a minimal group context: The self as an informational base. Journal of Personality and Social Psychology, 80, 188-205. doi:10.1037/0022-3514.80.2.188

Greenwald, A. G. (1980). The totalitarian ego: Fabrication and revision of personal history. American Psychologist, 35, 603-618. doi:10.1037/ 0003-066X.35.7.603

Haslam, S. A., Oakes, P. J., Reynolds, K. J., \& Turner, J. C. (1999). Social identity salience and the emergence of stereotype consensus. Personality and Social Psychology Bulletin, 25, 809-818. doi:10.1177/ 0146167299025007004

John, O. P., \& Srivastava, S. (1999). The Big Five trait taxonomy: History, measurement, and theoretical perspectives. In L. A. Pervin \& O. P. John (Eds.), Handbook of personality: Theory and research (2nd ed., pp. 102-138). New York, NY: Guilford Press.

Karniol, R. (2003). Egocentrism versus protocentrism: The status of self in social prediction. Psychological Review, 110, 564-580. doi:10.1037/ 0033-295X.110.3.564

Katz, D., \& Allport, F. H. (1931). Student attitudes. Syracuse, NY: Craftsman Press.

Kawada, C. L. K., Oettingen, G., Gollwitzer, P. M., \& Bargh, J. A. (2004). The projection of implicit and explicit goals. Journal of Personality and Social Psychology, 86, 545-559. doi:10.1037/0022-3514.86.4.545

Krosnick, J. A., Boninger, D. S., Chuang, Y. C., Berent, M. K., \& Carnot, C. G. (1993). Attitude strength: One construct or many related constructs? Journal of Personality and Social Psychology, 65, 1132-1151. doi:10.1037/0022-3514.65.6.1132

Krueger, J. I. (2003). Return of the ego-self-referent information as a filter for social prediction: Comment on Karniol (2003). Psychological Review, 110, 585-590. doi:10.1037/0033-295X. 110. 3. 585

Krueger, J. I. (2007). From social projection to social behaviour. European Review of Social Psychology, 18, 1-35. doi:10.1080/ 10463280701284645

Krueger, J. I., \& Stanke, D. (2001). The role of self-referent and otherreferent knowledge in perceptions of group characteristics. Personality and Social Psychology Bulletin, 27, 878-888. doi:10.1177/ 0146167201277010

Latrofa, M., Vaes, J., Cadinu, M., \& Carnaghi, A. (2010). The cognitive representation of self-stereotyping. Personality and Social Psychology Bulletin, 36, 911-922. doi:10.1177/0146167210373907 
Loersch, C., \& Payne, B. K. (2011). The situated inference model: An integrative account of the effects of primes on perception, behavior, and motivation. Perspectives on Psychological Science, 6, 234-252. doi: $10.1177 / 1745691611406921$

Lowery, B. S., Hardin, C. D., \& Sinclair, S. (2001). Social influence effects on automatic racial prejudice. Journal of Personality and Social Psychology, 81, 842-855. doi:10.1037/0022-3514.81.5.842

Marks, G., \& Miller, N. (1987). Ten years of research on the falseconsensus effect: An empirical and theoretical review. Psychological Bulletin, 102, 72-90. doi:10.1037/0033-2909.102.1.72

Markus, H. (1977). Self-schemata and processing information about the self. Journal of Personality and Social Psychology, 35, 63-78. doi: 10.1037/0022-3514.35.2.63

Maxwell, S. E., \& Delaney, H. D. (1993). Bivariate median splits and spurious statistical significance. Psychological Bulletin, 113, 181-190. doi:10.1037/0033-2909.113.1.181

McCall, C., \& Dasgupta, N. (2007). The malleability of men's gender self-concept. Self and Identity, 6, 173-188. doi:10.1080/ 15298860601115328

McCulloch, K. C., Ferguson, M. J., Kawada, C. C. K., \& Bargh, J. A. (2008). Taking a closer look: On the operation of nonconscious impression formation. Journal of Experimental Social Psychology, 44, 614623. doi:10.1016/j.jesp.2007.02.001

Mitchell, J. P., Banaji, M. R., \& Macrae, C. N. (2005). The link between social cognition and self-referential thought in the medial prefrontal cortex. Journal of Cognitive Neuroscience, 17, 1306-1315. doi:10.1162/ 0898929055002418

Monin, B. T., \& Norton, M. I. (2003). Perceptions of a fluid consensus: Uniqueness bias, false consensus, false polarization, and pluralistic ignorance in a water conservation crisis. Personality and Social Psychology Bulletin, 29, 559-567. doi:10.1177/0146167203029005001

Mussweiler, T. (2003). When egocentrism breeds distinctness-Comparison processes in social prediction: Comment on Karniol (2003). Psychological Review, 110, 581-584. doi:10.1037/0033-295X.110.3.581

Otten, S. (2004). Self-anchoring as predictor of in-group favoritism: Is it applicable to real group contexts? Cahiers de Psychologie Cognitive/ Current Psychology of Cognition, 22, 427-443.

Otten, S. (2005). The ingroup as part of the self: Reconsidering the link between social categorization, ingroup favoritism, and the self-concept. In M. D. Alicke, D. A. Dunning, \& J. I. Krueger (Eds.), The self in social judgment (pp. 241-265). New York, NY: Psychology Press.

Otten, S., \& Epstude, K. (2006). Overlapping mental representations of self, ingroup, and outgroup: Unraveling self-stereotyping and selfanchoring. Personality and Social Psychology Bulletin, 32, 957-969. doi:10.1177/0146167206287254

Patterson, M. M., Bigler, R. S., \& Swann, W. B., Jr. (2010). When personal identities confirm versus conflict with group identities: Evidence from an intergroup paradigm. European Journal of Social Psychology, 40, 652-670. doi:10.1002/ejsp.747

Peker, M. J., Crisp, R. J., \& Hogg, M. A. (2010). Predictors of ingroup projection: The roles of superordinate category coherence and complexity. Group Processes \& Intergroup Relations, 13, 525-542. doi:10.1177/ 1368430209360205

Pyszczynski, T., Greenberg, J., Solomon, S., Arndt, J., \& Schimel, J. (2004). Why do people need self-esteem? A theoretical and empirical review. Psychological Bulletin, 130, 435-468. doi:10.1037/0033-2909 .130 .3 .435

Ratcliff, R. (1993). Methods for dealing with reaction time outliers. Psychological Bulletin, 114, 510-532. doi:10.1037/0033-2909.114.3.510

Raudenbush, S. W., Bryk, A. S., Cheong, Y. F., \& Congdon, R. (2004). Hierarchical linear and nonlinear modeling (Version 6.01a) [Computer software]. Lincolnwood, IL: Scientific Software International.
Read, S. J., Vanman, E. J., \& Miller, L. C. (1997). Connectionism, parallel constraint satisfaction processes, and gestalt principles: (Re)introducing cognitive dynamics to social psychology. Personality and Social Psychology Review, 1, 26-53. doi:10.1207/s15327957pspr0101_3

Robbins, J. M., \& Krueger, J. I. (2005). Social projection to ingroups and outgroups: A review and meta-analysis. Personality and Social Psychology Review, 9, 32-47. doi:10.1207/s15327957pspr0901_3

Ross, L., Greene, D., \& House, P. (1977). The false consensus effect: An egocentric bias in social perception and attribution processes. Journal of Experimental Social Psychology, 13, 279-301. doi:10.1016/00221031(77)90049-X

Rothbart, M., \& Park, B. (1986). On the confirmability and disconfirmability of trait concepts. Journal of Personality and Social Psychology, 50, 131-142. doi:10.1037/0022-3514.50.1.131

Schwarz, N., \& Clore, G. L. (1983). Mood, misattribution, and judgments of well-being: Informative and directive functions of affective states Journal of Personality and Social Psychology, 45, 513-523. doi: 10.1037/0022-3514.45.3.513

Sedikides, C. (2003). On the status of self in social prediction: Comment on Karniol (2003). Psychological Review, 110, 591-594. doi:10.1037/ 0033-295X.110.3.591

Sherman, D. K., \& Kim, H. S. (2005). Is there an "I" in "team"? The role of the self in group-serving judgments. Journal of Personality and Social Psychology, 88, 108-120. doi:10.1037/0022-3514.88.1.108

Shrout, P. E., \& Bolger, N. (2002). Mediation in experimental and nonexperimental studies: New procedures and recommendations. Psychological Methods, 7, 422-445. doi:10.1037/1082-989X.7.4.422

Smith, E. R. (1996). What do connectionism and social psychology offer each other? Journal of Personality and Social Psychology, 70, 893-912. doi:10.1037/0022-3514.70.5.893

Smith, E. R., Coats, S., \& Walling, D. (1999). Overlapping mental representations of self, in-group, and partner: Further response time evidence and a connectionist model. Personality and Social Psychology Bulletin, 25, 873-882. doi:10.1177/0146167299025007009

Smith, E. R., \& Henry, S. (1996). An in-group becomes part of the self: Response time evidence. Personality and Social Psychology Bulletin, 22, 635-642. doi:10.1177/0146167296226008

Tajfel, H., \& Turner, J. C. (1986). The social identity theory of intergroup behavior. In S. Worschel \& W. G. Austin (Eds.), The social psychology of intergroup relations (pp. 7-24). Chicago, IL: Nelson-Hall.

Tropp, L. R., \& Wright, S. C. (2001). Ingroup identification as the inclusion of ingroup in the self. Personality and Social Psychology Bulletin 27, 585-600. doi:10.1177/0146167201275007

Turner, J. C., Hogg, M. A., Oakes, P. J., Reicher, S. D., \& Wetherell, M. S. (1987). Rediscovering the social group: A self-categorization theory. Cambridge, MA: Basil Blackwell.

Van Bavel, J. J., \& Cunningham, W. A. (2009). Self-categorization with a novel mixed-race group moderates automatic social and racial biases. Personality and Social Psychology Bulletin, 35, 321-335. doi:10.1177/ 0146167208327743

Van Boven, L., \& Loewenstein, G. (2003). Social projection of transient drive states. Personality and Social Psychology Bulletin, 29, 11591168. doi:10.1177/0146167203254597

Vargha, A. S., Rudas, T. S., Delaney, H. D., \& Maxwell, S. E. (1996). Dichotomization, partial correlation, and conditional independence. Journal of Educational and Behavioral Statistics, 21, 264-282. doi: $10.2307 / 1165272$

Received April 1, 2011

Revision received October 11, 2012 Accepted October 15, 2012 